\title{
SISTEMA COMBINADO DE FLOTAÇÃO POR AR DISSOLVIDO E FILTRAÇÃO ADSORTIVA EM ZEÓLITA PARA TRATAMENTO DE EFLUENTE DE REATOR UASB
}

\section{Combined system composed by dissolved air flotation-filtration-adsorption in zeolite for post-treatment of UASB reactor effluent}

\author{
Luiz Eduardo Moraes Casagrande ${ }^{1}$, Bruno de Oliveira Freitas ${ }^{2}$, Marcely Ferreira Nascimento ${ }^{3}$ \\ Recebido em 26 de novembro de 2015; recebido para revisão em 08 de março de 2016; aceito em 18 de abril de
} 2016; disponível on-line em 14 de junho de 2016.

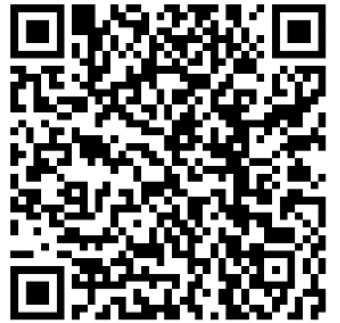

\section{PALAVRAS CHAVE:}

Tratamento avançado;

Filtração-adsortiva; Zeólita;

Flotação;

Reator Anaeróbio.

\section{KEYWORDS:}

Advanced Treatment;

Filtration-adsorption;

Zeolite;

Flotation;

Anaerobic Reactor

\footnotetext{
* Contato com os autores:
}

1 e-mail: luiz_mcasagrande@hotmail.com (L. E. M. Casagrande)

Engenheiro Ambiental pela Universidade Tecnológica Federal do Paraná

2e-mail: brunofreitas@utfpr.edu.br (B. O. Freitas)

Professor MSc. do Departamento de Engenharia Ambiental da Universidade Tecnológica Federal do Paraná - Campus Londrina.

3e-mail: marcely@iftm.edu.br (M. F. Nascimento)

MSc. em Tecnologia Ambiental e Recursos Hídricos, Professora do Instituto do Triângulo Mineiro - Campus Uberlândia. anaeróbio do tipo UASB é largamente utilizado no Brasil, porém esta tecnologia apresenta problemas em atender aos limites estabelecidos pela legislação brasileira para lançamento de efluente em termos de nitrogênio amoniacal, fósforo e matéria orgânica, pós-tratamento. Diante do potencial para remoção de matéria orgânica . filtrante, para pós-tratamento de efluente de reator UASB. Para tal, foram realizados ensaios de coagulação/floculação, flotação e filtração-adsortiva com um floteste adaptado com filtros adsorventes, utilizando efluente de reator anaeróbio do tipo UASB. Os resultados obtidos neste estudo atenderam aos padrões estabelecidos pela legislação brasileira para lançamento de efluentes em corpos d'água, alcançando $100 \%$ de

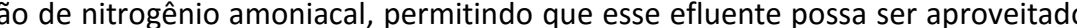
para reuso. Desse modo, o sistema de flotação com a filtração-adsortiva utilizando como meio filtrante mostrou-se eficiente na remoção de todos os poluentes

ABSTRACT: Among the existing solutions to sewage treatment, the UASB reactor is widely used in Brazil, but this technology has problem to attend the limits established by Brazilian law for discharging of effluent, especially to ammonia nitrogen, phosphorus and removal of organic matter and solids presents in anaerobic effluent, as well as the zeolite (he flotation followed by filtration-adsorption in bed composed by zeolite may be a promising alternative for post-treatment of this effluent. Therefore, the objective of the present study was to investigate the efficiency of a media for post-treatment of UASB reactor effluent. Coagulation/flocculation tests were performed, flotation and filtration-adsorption with an adsorbent filters fitted with Floteste (Bench equipment for flotation) using anaerobic effluent from the UASB reactor. The results obtained in this study met the standards established by the Brazilian legislation for discharging of effluents into water bodies, reaching $100 \%$ of ammonia nitrogen removal, allowing this wastewater can be reused. Thus, the flotation-filtrationadsorption system using zeolite as filter media proved to be effective as post-treatment of anaerobic effluent. The main contribution of this study was the assessment of a promising alternative for post-treatment of UASB effluent to meet the criteria of Brazilian legislation and to improve the quality of sewage treatment. 


\section{INTRODUÇÃO}

A expansão urbana associada ao crescimento populacional tem proporcionado o aumento da geração de esgoto sanitário nos centros urbanos. Uma das problemáticas que cerca esta questão está relacionada à implantação de sistema de saneamento básico eficiente que realize a coleta e o tratamento adequado do esgoto sanitário. Segundo a Pesquisa Nacional do Saneamento Básico (IBGE, 2010), em 2008 cerca de $55,2 \%$ dos municípios brasileiros possuíam sistema de esgotamento sanitário e apenas $28,5 \%$ dos municípios realizavam o tratamento do esgoto.

Dentre as soluções existentes para efetuar o tratamento de esgoto, o reator anaeróbio do tipo UASB tem sido largamente utilizado em todas as regiões do Brasil. Nesse tipo de reator, em que a biodegradação da matéria orgânica ocorre pela ação dos microrganismos anaeróbios, sabe-se dos problemas em atender os limites estabelecidos pela legislação brasileira com relação aos parâmetros nitrogênio amoniacal e fósforo, além de que as estações com esse tipo de reator podem ter problemas com a quantidade de matéria orgânica nos seus efluentes (CHERNICHARO et al., 2001; SOBRINHO e JORDÃO, 2001). Diante desta deficiência constata-se que é necessário implantar o pós-tratamento do efluente tratado em reatores anaeróbios de forma a incrementar a remoção de matéria orgânica, promover a remoção de constituintes como os nutrientes ( $N$ e $P$ ) e os organismos patogênicos (vírus, bactérias, protozoários e helmintos) que apresentam baixa remoção no tratamento anaeróbio.

Assim, o pós-tratamento do efluente tratado visa melhorar a qualidade microbiológica dos efluentes, atender as limitações impostas à utilização dos esgotos tratados na agricultura e diminuir os danos ambientais provocados pelas descargas remanescentes inadequadas em corpos receptores. Segundo Aisse et al. (2001), a flotação por ar dissolvido (FAD) é um método apropriado para pós-tratamento de efluente sanitário, alcançando bons níveis de qualidade, além de apresentar vantagens como a flexibilidade do processo, pois permite que se trabalhe em uma maior faixa de vazão de recirculação e de pressão, sendo possível o controle da quantidade de ar desprendida aliado ao pequeno tamanho das bolhas formadas.

A flotação combinada com agentes coagulantes pode remover sólidos em suspensão, matéria orgânica dissolvida e o fósforo, além de proporcionar a redução dos teores de gases odoríferos e elevação do nível de oxigênio dissolvido, o que resulta num efluente de melhor qualidade (AISSE et al., 2001). Em geral, o sistema combinado por reatores anaeróbios e flotação tem uma eficiência acima de $90 \%$ na remoção de matéria orgânica (com $\mathrm{DBO}_{5,20}$ residual menor que $40 \mathrm{mg} / \mathrm{L}$ ), sólidos em suspensão (geralmente menor que $50 \mathrm{mg} / \mathrm{L}$ ) e fósforo, menor que $1,0 \mathrm{mg} / \mathrm{L}$ (CAMPOS et al., 1996, REALI et al., 1998). Entretanto, a remoção do nitrogênio geralmente é baixa, variando entre 10 a 50\% (Santos, 2006), necessitando, assim, de um upgrade no processo de flotação por ar dissolvido, como, por exemplo, a floto-filtração, que une a flotação por ar dissolvido e a filtração em profundidade (Oliveira, 2007), com a utilização de meios granulares que promovam sua remoção, como a zeólita (Milan et al., 1997; Sardá, 2006 e Wang et al., 2007) para aumentar a remoção do nitrogênio amoniacal.

Dentre as características físico-químicas que as zeólitas apresentam destacam-se a capacidade de adsorção de gás e capacidade de troca catiônica. De acordo com Luz (1995), a alta eficiência de adsorção das zeólitas está relacionada com a grande superfície interna, devido sua estrutura cristalina ser caracterizada por cavidades espaçosas. Existem vários tipos de zeólitas naturais e sintéticas. As zeólitas naturais mais amplamente utilizadas são a mordenita, a clinoptilolita, a heulandita, a phillipsita, a erionita e a chabazita (LUZ, 1995). As zeólitas sintéticas são utilizadas como catalisadores devido à sua uniformidade na composição e elevado teor de pureza.

As zeólitas naturais têm sido as mais utilizadas no tratamento de água residuárias e de efluentes provenientes da suinocultura, para a remoção de amônia e, ainda, na remoção de íons 
metálicos tóxicos, tais como de cádmio, chumbo, arsênio e outros, pois nestes processos não há necessidade de elevada pureza da zeólita como nos processos catalíticos. A zeólita pode ser regenerada com salmoura, e a amônia adsorvida também pode ser recuperada, e usada na agricultura (LUZ, 1995; AGUIAR et al., 2002).

Sardá (2006) alcançou eficiência na remoção de nitrogênio amoniacal de 94,1\%, utilizando vazão de $71,67 \mathrm{~mL} / \mathrm{min}$, em estudo da influência da vazão sobre a cinética de adsorção do nitrogênio pelas zeólitas. Neste estudo observou-se ainda que quanto menor a vazão maior a remoção obtida, que, segundo Silva et al. (2007), ocorre devido ao elevado tempo de detenção no leito adsorvente.

Além da vazão, a relação da massa de zeólita por volume de solução é um importante fator para melhor eficiência de remoção do elemento desejado. Assim quanto maior for a razão (massa de zeólita/volume da solução) melhor será a eficiência de remoção do nutriente (FUNGARO e SILVA, 2002). Outro fator a ser considerado é a relação silício/alumínio do material, pois quanto menor a relação $\mathrm{Si} / \mathrm{Al}$ maior a capacidade de troca catiônica (SARDÁ, 2006).

Diante das características do efluente de reatores anaeróbios, do potencial de remoção de matéria orgânica e sólidos suspensos apresentados pela flotação e da eficiência que a zeólita apresenta na remoção de amônia, a associação dessas tecnologias pode ser uma promissora alternativa para tratamento de esgoto sanitário.

Em razão do exposto, a presente pesquisa visou avaliar a eficiência de um sistema de flotação associado à filtração-adsortiva no pós-tratamento de efluente de reator UASB, buscando uma alternativa que atendesse aos padrões da legislação brasileira e melhorasse a qualidade dos efluentes sanitários.

\section{OBJETIVO}

O presente trabalho teve como objetivo avaliar a eficiência de remoção de matéria orgânica, sólidos totais e nitrogênio de efluentes de reatores anaeróbios utilizando a flotação, seguida de filtração-adsortiva em zeólita, como alternativa para pós-tratamento.

\section{METODOLOGIA}

\subsection{DADOS GERAIS}

O trabalho experimental foi desenvolvido no Laboratório de Saneamento da Universidade Tecnológica Federal do Paraná (UTFPR) - Campus Londrina, onde o sistema de bancada foi montado para realização dos ensaios de coagulação, floculação, flotação e filtraçãoabsortiva. O efluente utilizado no estudo foi proveniente de reator anaeróbio do tipo UASB, da ETE Zona Norte da Companhia de Saneamento do Paraná (SANEPAR) localizada na cidade de Londrina-PR. Durante o desenvolvimento do estudo foram realizadas coletas semanais de efluente do reator anaeróbio, dentro de um período de seis semanas.

A coleta de esgoto tratado era realizada em duas bombonas plásticas de 20 litros cada. Após coleta, o esgoto tratado era armazenado na geladeira, a $4^{\circ} \mathrm{C}$, até o momento da realização dos ensaios experimentais, para evitar a degradação do efluente, como recomendado por APHA (2012).

Os ensaios foram divididos em duas etapas. Na primeira etapa foram realizados ensaios de coagulação/floculação e flotação em aparelho floteste e na segunda etapa foram realizados os ensaios de floto-adsorção, em floteste adaptado com filtros adsorventes.

\subsection{ENSAIOS DE COAGULAÇÃO/FLOCULAÇÃO E FLOTAÇÃO}

Após caracterização do efluente do reator UASB, foram realizados ensaios de coagulação/floculação e flotação, em floteste (Figura 1), utilizando o Policloreto de Alumínio (PAC) como coagulante, em concentrações prédeterminadas de 45,0; 67,5 e 90,0 mg/L de $\mathrm{Al}_{2} \mathrm{O}_{3}$ na forma de PAC, em valores de $\mathrm{pH}$ de 6,5, 7,27 e 7,5 para definição da dosagem e pH que proporcionariam a maior eficiência na redução de turbidez e cor após a flotação. 


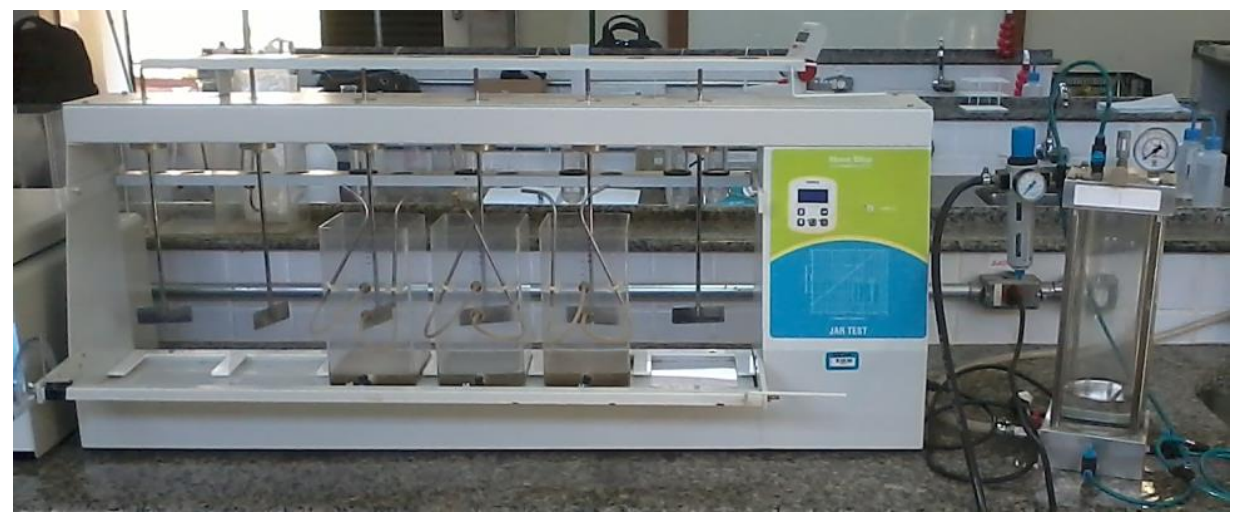

FIGURA 1: Floteste - Equipamento utilizado para realização dos ensaios de coagulação/floculação e flotação .

FONTE: Casagrande (2014).

O coagulante PAC foi fornecido na forma líquida pela Indústria Faxon Química, com 16 a $20 \%$ de óxido de alumínio $\left(\mathrm{Al}_{2} \mathrm{O}_{3}\right)$. Este coagulante foi escolhido para o estudo, pois de acordo com Pavanelli (2001) proporciona eficiência elevada no processo, em media de 1,5 a 2,5 vezes superior, em igual dosagem em íon $\mathrm{Al}^{3+}$ quando comparado a outros sais de alumínio habitualmente utilizados.

$\mathrm{Na}$ etapa de coagulação foi utilizado o gradiente de velocidade de $800 \mathrm{~s}^{-1}$ e um tempo de mistura rápida de 15 segundos. Após a mistura rápida, o gradiente de velocidade era reduzido para $80 \mathrm{~s}^{-1}$, por um período de 10 minutos, simulando o processo de floculação, de acordo com as recomendações da NBR 12209 (ABNT, 2011). Para a etapa de flotação foi utilizada pressão de saturação de 5 bar, com taxa de recirculação de $20 \%$ e velocidade de flotação de $16 \mathrm{~cm} \cdot \mathrm{min}^{-1}$, condições utilizadas por Ariano (2009). O tempo de coleta de 30s foi calculado pelo método de DANTAS et al. (2008). Durante a realização dos experimentos optou-se por avaliar a dosagem de $9,0 \mathrm{mg} / \mathrm{L}$ de $\mathrm{Al}_{2} \mathrm{O}_{3}$ na forma de $\mathrm{PAC}$, concentração dez vezes menor que a utilizada anteriormente na fase de seleção da concentração do coagulante, em virtude de Ariano (2009) ter alcançado excelentes resultados utilizando dosagem de $\quad 8,45 \mathrm{mg} / \mathrm{L} \mathrm{de}$ $\mathrm{Al}_{2} \mathrm{O}_{3}$ na forma de PAC em estudo empregando flotação no pós-tratamento de efluentes de reatores anaeróbios. Os demais parâmetros foram mantidos para comparação dos resultados entre as duas concentrações estudadas.

\subsection{ENSAIOS DE FLOTO-ADSORÇÃO}

Para realização dos ensaios de floto-adsorção os filtros adsorventes foram adaptados ao floteste (Figura 2).

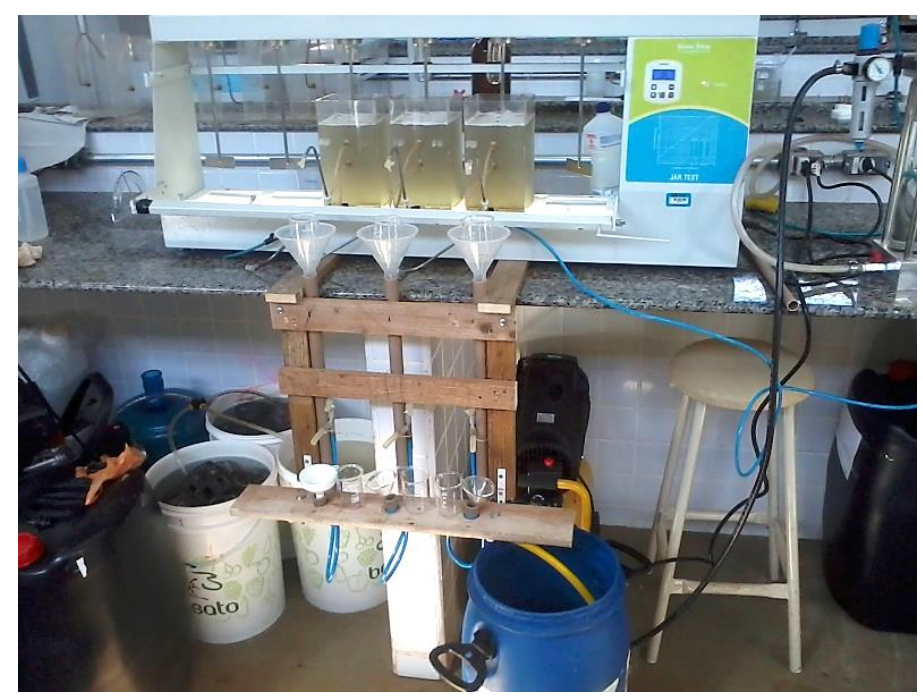

FIGURA 2: Floteste adaptado com filtros adsorventes. FONTE: Casagrande (2014). 
Os filtros foram confeccionados em tubos de PVC de $20 \mathrm{~mm}$ de diâmetro e $50 \mathrm{~cm}$ de altura, com três colunas em paralelo, como mostrado na Figura 3.

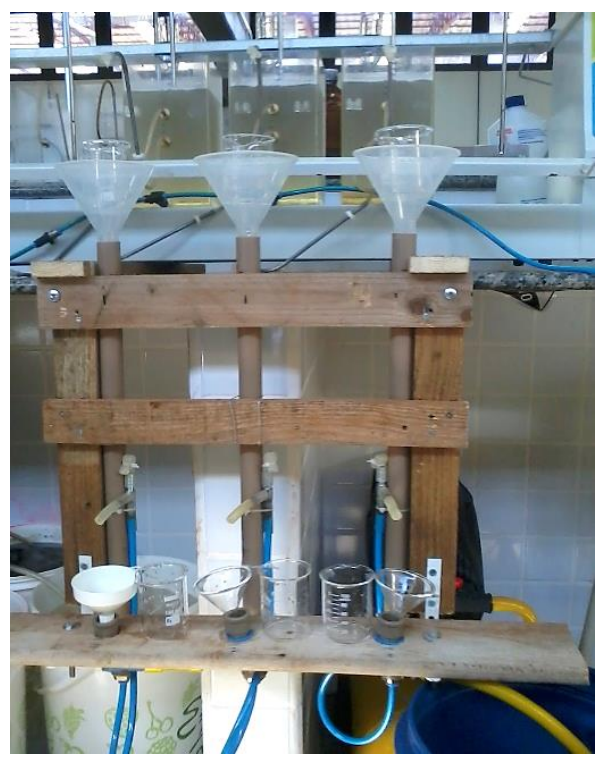

FIGURA 3: Colunas de filtração-adsortiva. FONTE: Casagrande (2014).

Os filtros adsorventes foram preenchidos com $3,0 \mathrm{~cm}$ de cascalho e $15,0 \mathrm{~cm}$ de zeólita, com granulometria entre 0,85 e $1,18 \mathrm{~mm}$. A granulometria escolhida para o trabalho seguiu recomendações de Kurama et al. (2010), que, em estudos realizados em colunas de adsorção concluiu que a granulometria inferior a $0,6 \mathrm{~mm}$ não permite permeabilidade apropriada para este tipo de ensaio. Os filtros foram operados a taxa de aplicação superficial de 200 a $300 \mathrm{~m}^{3} \cdot \mathrm{m}^{-2} \cdot \mathrm{d}^{-1}$, como recomendado por METCALF \& EDDY (2003) e OLIVEIRA (2007).

A zeólita utilizada nos experimentos foi obtida da empresa Klintex, com nome de AQUAFIL $N$ 10. Segundo as informações da empresa esta zeólita é natural composta por minerais de heulandita, clinoptilolita e mordenita e é indicada para a remoção de amônia, fosfato e nitrato.

Após o tempo de coleta para a flotação, eram realizadas as coletas das amostras dos três jarros. Em seguida à retirada das amostras, iniciavase a filtração-adsortiva. Ao longo dos primeiros sete minutos (tempo de detenção do filtro) o filtrado era descartado. Após esse período, era realizada a coleta de aproximadamente $100 \mathrm{~mL}$ da amostra de cada filtro-adsortivo para determinação dos parâmetros físico-químicos. As amostras dos filtros-adsortivos eram misturadas em uma garrafa para que proporcionasse uma única amostra das três colunas de adsorção. Antes e depois de cada experimento era realizada a retrolavagem dos filtros, como recomendado por Dantas et al. (2008).

\subsection{AMOSTRAGEM E PARÂMETROS MONITORADOS DURANTE OS EXPERIMENTOS}

Antes dos ensaios de coagulação/floculação/flotação era realizada a caraterização do efluente do reator UASB com a determinação dos seguintes parâmetros: $\mathrm{pH}$, cor aparente, alcalinidade total, demanda química de oxigênio total (DQOt), turbidez, nitrogênio amoniacal (N-Amoniacal), sólidos totais (ST), sólidos totais fixos (STF) e sólidos totais voláteis (STV).

Após os ensaios de coagulação/floculação/flotação, a fim de avaliar a eficiência da flotação empregada neste estudo, eram realizadas as seguintes análises físicoquímicas: DQO, N-Amoniacal, ST, cor e turbidez. Estas mesmas análises eram realizadas após os ensaios de floto-adsorção, em todas as análises foram utilizados os métodos descritos na 22a edição do Standard methods for the examination of water and wastewater (APHA, 2012).

\section{RESULTADOS}

\subsection{AVALIAÇÃO DA DOSAGEM DE COAGULANTE}

Para a avaliação da dosagem de PAC a ser utilizada, foram estudadas três diferentes concentrações do coagulante visando analisar a influência das diferentes concentrações na redução das variáveis físicas, cor aparente e turbidez via o processo de flotação. Na Tabela 1 são apresentados os valores de turbidez e cor obtidos, variando o $\mathrm{pH}$ do efluente do reator UASB e a concentração do coagulante PAC.

A partir dos resultados obtidos e apresentados na Tabela 1 , foi escolhida a concentração de $90 \mathrm{mg} / \mathrm{L}$ de $\mathrm{Al}_{2} \mathrm{O}_{3}$ na forma de PAC como concentração ideal para realização dos ensaios de flotação em virtude dos valores baixos 
de turbidez e cor aparente residual obtidos para $\mathrm{pH}$ de 7,27 e de 7,5.

Como mencionado anteriormente, durante os experimentos foi ainda avaliada a dosagem de 9,0 mg/L de $\mathrm{Al}_{2} \mathrm{O}_{3}$ na forma de PAC, concentração dez vezes menor que a utilizada anteriormente. Desta forma, a eficiência do sistema foi avaliada com a utilização das duas concentrações mencionadas.
4.2 AVAliação do SISTEMA DE FLOTOADSORÇÃO

4.2.1 Desempenho do sistema de floto-adsorção utilizando $90 \mathrm{mg} / \mathrm{L}$ de $\mathrm{Al}_{2} \mathrm{O}_{3}$ na forma de $\mathrm{PAC}$.

A caracterização do efluente do reator UASB, realizada antes de cada ensaio de flotação e filtração-adsortiva utilizando concentração de coagulante 90 mg/l está apresentada na Tabela 2.

TABELA 1: Variações de pH do efluente e da concentração do PAC analisadas.

\begin{tabular}{|c|c|c|c|}
\hline $\begin{array}{c}\text { Valores } \\
\text { de } \mathrm{pH}\end{array}$ & $\begin{array}{c}\text { PAC } \\
\left(\mathrm{mg} / \mathrm{L} \text { de } \mathrm{Al}_{2} \mathrm{O}_{3}\right)\end{array}$ & $\begin{array}{l}\text { Turbidez residual } \\
\text { (NTU) }\end{array}$ & $\begin{array}{c}\text { Cor } \\
\text { aparente } \\
\text { (PtCo) }\end{array}$ \\
\hline \multirow{3}{*}{6,5} & 45 & 2 & 8 \\
\hline & 67,5 & 4 & 10 \\
\hline & 90 & 17 & 65 \\
\hline \multirow{3}{*}{7,27} & 45 & 3 & 12 \\
\hline & 67,5 & 19 & 13 \\
\hline & 90 & 2 & 9 \\
\hline \multirow{3}{*}{7,5} & 45 & 4 & 12 \\
\hline & 67,5 & 1 & 8 \\
\hline & 90 & 1 & 8 \\
\hline
\end{tabular}

TABELA 2: Caracterização do efluente do reator UASB para os ensaios utilizando concentração de $90 \mathrm{mg} / \mathrm{l}$ de $\mathrm{Al}_{2} \mathrm{O}_{3}$ na forma de PAC.

\begin{tabular}{c|c|c|c|c|c} 
Parâmetros & Experimento 1 & Experimento 2 & Experimento 3 & Média & $\begin{array}{c}\text { Desvio } \\
\text { padrão }\end{array}$ \\
\hline pH & 7,20 & 6,90 & 7,20 & 7,10 & 0,17 \\
\hline Turbidez (NTU) & 68 & 105 & 79 & 84 & 19 \\
\hline Cor Aparente (PtCo) & 295 & 194 & 361 & 283 & 84 \\
\hline DQOt (mg/L) & 267 & 212 & 218 & 232 & 30 \\
\hline Alcalinidade (mg de CaCO3/L) & 248 & 282 & 231 & 254 & 25 \\
\hline Nitrogênio Amoniacal (mg/L) & 25 & 38 & 35 & 33 & 10 \\
\hline ST (mg/L) & 607 & 570 & 418 & 532 & 99 \\
\hline STF (mg/L) & - & - & 181 & - & - \\
\hline STV (mg/L) & - & - & 237 & - & - \\
\hline
\end{tabular}


Como pode ser verificado na Tabela 2, os valores de $\mathrm{pH}$ do efluente do reator UASB permaneceram próximo à neutralidade, entre 6,5 e 7,5 , dentro da faixa apropriada para a coagulação (AISSE, 2001), não necessitando assim de correção.

Com relação aos resultados de sólidos totais, o efluente do reator UASB apresentou valor médio de $532 \mathrm{mg} / \mathrm{L}$, ficando mais alto que o valor médio obtido por Santos (2006) que foi de $376 \mathrm{mg} / \mathrm{L}$. Já o valor médio de DQOt obtido (232 mg/L), ficou próximo ao encontrado por Reali (1998), de $258 \mathrm{mg} / \mathrm{L}$. É importante ressaltar que o reator UASB apresenta boa remoção de matéria orgânica biodegradável (55 a 75\%) e praticamente nenhuma eficiência de remoção de nitrogênio (SOBRINHO, 2001).

Após a caracterização do efluente foram realizados os ensaios de flotação, seguida de filtração-adsortiva. Na Tabela 3 são apresentados os valores médios de concentração e eficiência de remoção dos parâmetros analisados.

A partir dos valores apresentados na Tabela 3 observa-se que o efluente do reator UASB ao passar pelo sistema de pós-tratamento proposto atingiu um padrão de qualidade elevado, apresentando boa eficiência de remoção dos poluentes. Avaliando os valores dos parâmetros turbidez, cor e DQOt observa-se que houve uma baixa remoção no efluente final devido ao bom desempenho da flotação. Com relação à série de sólidos foram obtidas elevadas eficiências de remoção devido a grande capacidade de retenção de partículas pelo meio filtrante.

É importante destacar o excelente desempenho do sistema na remoção de nitrogênio amoniacal, com eficiência média de $100 \%$, semelhantemente à alcançada por Sardá (2006) que obteve 94\% com efluente de granja de suínos e Widiastuti et al. (2011) que obteve até $97 \%$ de remoção de nitrogênio de águas cinzas.

\subsubsection{Desempenho do sistema de floto-adsorção utilizando $9,0 \mathrm{mg} / \mathrm{L}$ de $\mathrm{Al}_{2} \mathrm{O}_{3}$ na forma de $\mathrm{PAC}$.}

A caracterização do efluente do reator UASB, realizada antes de cada ensaio de flotação e filtração-adsortiva utilizando concentração de coagulante $9,0 \mathrm{mg} / \mathrm{L}$ está apresentada na Tabela 4.

A partir da Tabela 4 observa-se que o valor médio de $\mathrm{pH}$ do efluente do reator UASB manteve-se na faixa apropriada para a coagulação, permanecendo próximo a neutralidade. $O$ valor médio de turbidez se assemelha ao obtido por Reali (1998), igual a 104 NTU. Já o valor médio de cor aparente ficou um pouco a baixo do encontrado pelo mesmo autor, igual a $492 \mathrm{uC}$.

Com relação aos resultados de sólidos (totais, fixos e voláteis) obtidos para o efluente do reator UASB, nota-se que a matéria orgânica é responsável pela grande quantidade de sólidos totais encontrados. O valor médio de DQOt ficou próximo aos obtidos por Filho e Brandão (2000), que variaram entre 279 e 542 mg/L. A média de nitrogênio amoniacal registrada nesta etapa do trabalho foi um pouco superior ao obtido na etapa anterior, mas permaneceu do esperado, por exemplo comparando a média de Sousa (2000), de $45 \mathrm{mg} / \mathrm{L}$.

TABELA 3: Valores médios de concentração e eficiência de remoção para os parâmetros analisados.

\begin{tabular}{c|c|c|c|c|c|c}
\multirow{2}{*}{ Parâmetro } & \multicolumn{3}{|c|}{ Efluente Flotado } & \multicolumn{3}{c}{ Efluente Final } \\
\cline { 2 - 7 } & Média & $\begin{array}{c}\text { Desvio } \\
\text { padrão }\end{array}$ & Remoção (\%) & Média & $\begin{array}{c}\text { Desvio } \\
\text { padrão }\end{array}$ & Remoção (\%) \\
\hline Turbidez (NTU) & 2 & 1 & 97 & 1 & 0,5 & 50 \\
\hline Cor Aparente (PtCo) & 10 & 8 & 96 & 7 & 5 & 31 \\
\hline DQO (mg/L) & 33 & 13 & 85 & 22 & 2 & 34 \\
\hline Nitrogênio Amoniacal (mg/L) & 28 & 5 & 14 & 0 & 0 & 100 \\
\hline ST (mg/L) & 217 & 71 & 59 & 60 & 54 & 72 \\
\hline
\end{tabular}


TABELA 4: Caracterização do efluente do reator UASB para os ensaios utilizando concentração de $9,0 \mathrm{mg} / \mathrm{l} \mathrm{de}$ $\mathrm{Al}_{2} \mathrm{O}_{3}$ na forma de PAC.

\begin{tabular}{c|c|c|c|c|c}
\hline Parâmetros & Experimento 1 & Experimento 2 & Experimento 3 & Média & $\begin{array}{c}\text { Desvio } \\
\text { padrão }\end{array}$ \\
\hline pH & 7,00 & 7,10 & 7,40 & 7,17 & 0,20 \\
\hline Turbidez (NTU) & 84 & 131 & 231 & 149 & 75 \\
\hline Cor Aparente (PtCo) & 330 & 436 & 428 & 398 & 59 \\
\hline DQO (mg/L) & 326 & 314 & 284 & 308 & 21 \\
\hline $\begin{array}{c}\text { Alcalinidade } \\
\text { (mg de CaCO)/L) }\end{array}$ & 321 & 335 & 333 & 330 & 7 \\
\hline N-Amoniacal (mg/L) & 37 & 41 & 38 & 38 & 2 \\
\hline ST (mg/L) & 435 & 792 & 560 & 595 & 181 \\
\hline STF (mg/L) & 167 & 350 & 207 & 241 & 95 \\
\hline STV (mg/L) & 267 & 442 & 352 & 354 & 87 \\
\hline
\end{tabular}

FONTE: Os autores.

Assim como nos ensaios anteriores, após a caracterização do efluente eram realizados os ensaios de flotação, seguida de filtração-adsortiva. Na Tabela 5 são apresentados os valores médios de concentração e eficiência de remoção dos parâmetros analisados.

Analisando os dados da Tabela 5 observase que, mesmo com redução na concentração de coagulante, a utilização de meio filtrante de zeólita forneceu boa qualidade do efluente final, apresentando valores abaixo dos padrões de lançamento de efluentes exigidos pela legislação ambiental brasileira, apresentando $100 \%$ de remoção de nitrogênio amoniacal presente no efluente do reator UASB.

Nesta etapa do trabalho a remoção de sólidos na filtração-adsortiva não foi eficiente quando comparados com os valores da primeira etapa, a qual pode ter sido influenciada pela maior concentração de sólidos totais presente no efluente UASB nestes dias o que pode ter relação com o menor desempenho do processo de flotação para os sólidos totais.

$\mathrm{Na}$ Tabela 6 são apresentadas as eficiências de remoções obtidas utilizando concentração de 90 e de $9,0 \mathrm{mg} / \mathrm{L}$ de $\mathrm{Al}_{2} \mathrm{O}_{3}$ na forma de PAC.

TABELA 5: Valores médios de concentração e eficiência de remoção para os parâmetros analisados.

\begin{tabular}{c|c|c|c|c|c|c}
\multirow{2}{*}{ Parâmetro } & \multicolumn{3}{|c|}{ Efluente Flotado } & \multicolumn{3}{c}{ Efluente Final } \\
\cline { 2 - 7 } & Média & $\begin{array}{c}\text { Desvio } \\
\text { padrão }\end{array}$ & Remoção (\%) & Média & $\begin{array}{c}\text { Desvio } \\
\text { padrão }\end{array}$ & Remoção (\%) \\
\hline Turbidez (NTU) & 36 & 16 & 70 & 8 & 5 & 77 \\
\hline Cor Aparente (PtCo) & 120 & 26 & 75 & 39 & 8 & 67 \\
\hline DQO (mg/L) & 109 & 11 & 65 & 56 & 21 & 48 \\
\hline Nitrogênio Amoniacal (mg/L) & 30 & 3 & 21 & 0 & 0 & 100 \\
\hline ST (mg/L) & 343 & 64 & 42 & 242 & 112 & 29 \\
\hline STF (mg/L) & 168 & 89 & 30 & 117 & 77 & 30 \\
\hline STV (mg/L) & 174 & 96 & 50 & 125 & 89 & 28 \\
\hline
\end{tabular}


TABELA 6: Valores médios de remoção para os parâmetros analisados utilizando concentração de 90 e de 9,0 mg/L de $\mathrm{Al}_{2} \mathrm{O}_{3}$ na forma de PAC.

\begin{tabular}{|c|c|c|}
\hline Parâmetros & $\begin{array}{l}\text { Eficiência de remoção }(90,0 \mathrm{mg} / \mathrm{L} \text { de } \\
\left.\qquad \mathrm{Al}_{2} \mathrm{O}_{3}(\%)\right)\end{array}$ & $\begin{array}{l}\text { Eficiência de remoção }(9,0 \mathrm{mg} / \mathrm{L} \text { de } \\
\left.\qquad \mathrm{Al}_{2} \mathrm{O}_{3}(\%)\right)\end{array}$ \\
\hline Turbidez (NTU) & 98 & 94 \\
\hline Cor Aparente (PtCo) & 97 & 90 \\
\hline $\mathrm{DQO}(\mathrm{mg} / \mathrm{L})$ & 90 & 82 \\
\hline N-Amoniacal (mg/L) & 100 & 100 \\
\hline Sólidos Totais (mg/L) & 89 & 59 \\
\hline
\end{tabular}

Como pode ser observado na Tabela 6, com o sistema proposto foi possível alcançar ótimos resultados, principalmente para o nitrogênio amoniacal, parâmetro com eficiência de remoção de 100\%. Observou-se ainda que houvesse pequena redução de eficiências de remoção dos parâmetros turbidez, cor e DQOt, quando a menor concentração de coagulante foi utilizada (9,0 mg/L), sendo que para o parâmetro nitrogênio amoniacal não houve perda de eficiência.

Com relação à remoção de sólidos totais foi verificado uma diminuição de eficiência para os ensaios com $9,0 \mathrm{mg} / \mathrm{L}$ de $\mathrm{Al}_{2} \mathrm{O}_{3}$ que pode ter influência direta da utilização de menor dosagem de coagulante. Porém, é importante destacar que a remoção de quase $60 \%$ de sólidos totais já pode ser considerada satisfatória. Desta forma, a utilização de meio filtrante de zeólita é eficiente na redução de sólidos, assim como filtros compostos por areia, com a vantagem de remover o nitrogênio.

Os valores obtidos, além de atender às exigências da legislação brasileira para lançamento de efluentes em corpos d'água, permitem que o efluente possa ser aproveitado para reuso. Considerando a classificação de reuso da NBR 13969 (ABNT, 1997), o efluente final obtido pode ser aproveitado para lavagem de carros, pisos, calçadas e irrigação de jardim, segundo a característica de turbidez exigida pela referida norma, que deve ser menor que 5,0 NTU.

\section{CONSIDERAÇÕES FINAIS}

Os resultados obtidos neste estudo atenderam aos padrões determinados pela legislação. Desse modo, o sistema de flotação com a filtração-adsortiva com zeólita mostrou-se eficiente na remoção de todos os poluentes avaliados.

As duas concentrações de $\mathrm{Al}_{2} \mathrm{O}_{3}$ na forma de PAC (90 mg/L e 9,0 mg/L) avaliadas no sistema de flotação-filtração-adsortiva promoveram elevadas eficiências de remoção dos poluentes analisados, exceto para a remoção de sólidos totais, no qual a concentração de $9,0 \mathrm{mg} / \mathrm{L}$ apresentou menor desempenho.

A partir da caracterização do efluente antes e depois da filtração-adsortiva, é possível concluir que houve remoção de sólidos totais fixos e voláteis tanto por flotação quanto por filtraçãoadsortiva.

A filtração-adsortiva com utilização de zeólita comercial composta por minerais de heulandita, clinoptilolita e mordenita utilizada como meio filtrante-adsorvente, apresenta elevada capacidade de remoção de nitrogênio amoniacal, alcançando eficiência de $100 \%$ de remoção sob as taxas de aplicação superficial indicadas para filtração de esgoto sanitário.

Desta forma, esta pesquisa apresenta o sistema combinado de flotação e filtração-adsortiva como uma promissora alternativa para pós-tratamento 
de efluente de reator UASB, apresentando melhoria na qualidade dos efluentes sanitários e atendendo as exigências da legislação brasileira para lançamento de efluentes em corpos d'água.

\section{AGRADECIMENTOS}

Os autores agradecem à Companhia de Saneamento do Paraná (Sanepar) por viabilizar parte da pesquisa.

\section{REFERÊNCIAS BIBLIOGRÁFICAS}

AGUiAR, M. R. M. P. ; NOVAES, A. C.; GUARINO, A. W. S. Remoção de metais pesados de efluentes industriais por aluminossilicatos. Química Nova, v. 25, n. 6b, 2002, 1145-1154 p.

AISSE, M. M.; JÜRGENSEN, D.; REALI, M. A.; PENETRA, R. G.; FLORENCIO, L.; ALEM SOBRINHO, P. Pós-tratamento de efluentes de reatores anaeróbios por sistema de flotação. In: Chernicharo, Carlos. A. de L. Pós-tratamento de efluentes de reatores anaeróbios. Belo Horizonte, 2001.

AMERICAN PUBLIC HEALTH ASSOCIATION - APHA; AWWA, WEF. Standard methods for the examination of water and wastewater. 22 ed. Washington: American Public Health Association, 2012.

ARIANO, G. C. Coagulação, floculação e flotação do efluente de reatores anaeróbios, tratando esgoto sanitário, com aplicação de diferentes dosagens de coagulante em função da variação da turbidez do esgoto afluente ao longo do dia. Dissertação (Mestrado em Hidráulica e Saneamento) - Escola de Engenharia de São Carlos/USP. São Carlos, SP, 2009.193 p.

ASSOCIAÇÃO BRASILEIRA DE NORMAS TÉCNICAS, NBR 12209: Projeto de estações de tratamento de esgoto sanitário. Rio de Janeiro, 2011.

NBR 13969: Tanques sépticos - Unidades de tratamento complementar e disposição final dos efluentes líquidos - Projeto, construção e operação. Rio de Janeiro, 1997.

CASAGRANDE, L. E. M. Sistema de bancada de flotação por ar dissolvido e filtração-adsortiva para tratamento de efluentes de reatores anaeróbios. Monografia (Trabalho de Conclusão do Curso Superior em Engenharia Ambiental). Universidade Tecnológica Federal do Paraná. Londrina, PR, 2014, 63p.
CAMPOS, J. R. ; REALI, M. A. P.; DOMBROSKI, S. A. G.; MARCHETTO, M.; LIMA, M. R. A. Tratamento físicoquímico por flotação de efluentes de reatores anaeróbios. Departamento de Hidráulica e Saneamento - Escola de Engenharia de São Carlos. São Carlos - SP, 1996.

CHERNICHARO, C. ; SILVA COTA, R.; ZERBINI, A. M.; VON SPERLING, M.; CASTRO BRITO, L. N. Post-treatment of anaerobic effluents in an overland flow system. Water Science and Technology, v. 44, n.4, 2001, 229-36 p.

DANTAS, A. D; Di BERNARdo, L.; VOLTAN, P. E. N. Controle básico de ETAs 1 - Coagulação: nível 2: ReCESA, 2008.

FILHO, A. C. T. P; BRANDÃO, C.. C. S. Avaliação do potencial da flotação por ar dissolvido sob pressão como pós-tratamento para efluentes de reatores anaeróbios de fluxo ascendente. In: Congresso Interamericano de Engenharia Sanitária e Ambiental, XVII, Porto Alegre - RS, 2000.

FUNGARO, D. A; SILVA, M. G. Utilização de zeólita preparada a partir de cinzas residuária de carvão como adsorvedor de metais em água. Química Nova, v. 25, n. 6B, 2002, 1081-1085 p.

IBGE - INSTITUTO BRASILEIRO DE GEOGRAFIA E ESTATÍSTICA. Pesquisa Nacional de Saneamento Básico, 2008. Rio de Janeiro: IBGE, 2010. 219p.

KURAMA, H. ; KARAGÜZEL, C.; MERGAN, T.; ÇELIK, M. S. Ammonium removal from aqueous solutions by dissolved air flotation in the presence of zeolite carrier. Desalination, v. 253, n. 1, 2010, 147-152 p.

LUZ, A. B. Zeólitas: Propriedades e usos industriais. Rio de Janeiro: CETEM/CNPq, 1995.

METCALF \& EDDY. Wastewater Engineering: Treatment and Reuse. 4. ed., Mc Graw Hill. New York, 2003.

MILAN, Z. ; SANCHEZ, E.; WEILAND, P.; DE LAS POZAS, C.; BORJA, R.; MAYARI, R.; ROVIROSA, N. Ammonia removal from anaerobically treated piggery manure by ion exchange in columns packed with homoionic zeolite. Chemical Engineering Journal, v. 66, n.1, 1997 65-71 p.

OLIVEIRA, A.L. Floto-filtração como pós-tratamento do efluente de reator anaeróbio tratando esgoto sanitário. Tese (Doutorado em Hidráulica e Saneamento) - Escola de Engenharia de São Carlos/USP. São Carlos, SP, 2007, $209 \mathrm{p}$. 
PAVANELLI, G. Eficiência de diferentes tipos de coagulação na coagulação, floculação e sedimentação de água com cor ou turbidez elevada. Dissertação (Mestrado em Hidráulica e Saneamento) - Escola de Engenharia, Universidade de São Paulo, São Carlos, 2001, 233 p.

REALI, M. A. P.; PENETRA R. G.; CAMPOS, J. R. Influência da floculação na flotação de efluentes de reatores anaeróbios (UASB). Departamento de Hidráulica e Saneamento - Escola de Engenharia de São Carlos, USP. São Carlos, SP, 1998.

SANTOS, H. R. Coagulação/Precipitação de efluentes de reatores anaeróbios de leito expandido e de sistema de lodo ativado precedido de reatores UASB, com remoção de partículas por sedimentação ou flotação. Tese (Doutorado em Hidráulica e Saneamento) - Escola de Engenharia de São Carlos/USP. São Carlos, SP, 2006, $331 \mathrm{p}$.

SARDÁ, L. G. A utilização da zeólita na remoção de nutrientes do efluente de dejetos suínos. Monografia (Trabalho de conclusão do Curso Superior de Engenharia Agronômica) - Universidade Federal de Santa Catarina. Florianópolis, SC, 2006, 40 p.

SILVA, A. G.; PONTES, L. A. M.; DOS SANTOS, E. G. Adsorção da parafina C12 em coluna de leito fixo de zeólita 5A. Anais do $4^{\circ}$ PDPETRO, Campinas, 2007.

SOBRINHO, P. A; JORDÃO. E. P. Pós-tratamento de efluentes de reatores anaeróbios - Uma análise crítica. In: Chernicharo, Carlos. A. de L. Pós-tratamento de efluentes de reatores anaeróbios. Belo Horizonte, 2001.

SOUSA, J. T. ; VAN HAANDEL, A. C.; DA SILVA COSENTINO, P. R.; GUIMARÃES, A. V. A. Pós-tratamento de efluente de reator UASB utilizando sistemas "wetlands" construídos. Revista Brasileira de Engenharia Agrícola e Ambiental, v.4, n.1, 2000, 87-91 p.

WANG, Y.; KMIYA, Y.; OKUHARA, T. Removal of lowconcentration ammonia in water by ion-exchange using Na-mordenite. Water research, v. 41, n. 2, 2007, 269$276 \mathrm{p}$.

WIDIASTUTI, N.; WU, H.; ANG, H. M.; ZHANG, D. Removal of ammonium from greywater using natural zeolite. Desalination, vol. 277, n. 1, 2011, 15-23 p. 